\title{
The influence of the age of dementia onset on college students' stigmatic attributions towards a person with dementia
}

\author{
Perla Werner $^{1^{*}}$ (D), Lilach Raviv-Turgeman ${ }^{1}$ and Patrick W. Corrigan ${ }^{2}$
}

\begin{abstract}
Background: Research in the area of public stigma and Alzheimer's disease (AD) is limited to examining stigmatic beliefs towards persons aged 65 and over (i.e., persons with late-onset dementia). The aim of the present study was to compare college students' stigmatic attributions towards an older and a younger person with $A D$, using an attributional model of stigma.

Method: A cross-sectional study was conducted with 375 college students (mean age $=25.5,58.9 \%$ female, 64.3\% Jewish) who answered a computerized, self-administered, structured questionnaire after being presented with one of two randomly distributed vignettes varying in the age of the person with $A D-80$ or 50 years of age. Cognitive, emotional and behavioral attributions of stigma were assessed using an adapted version of the Attribution Questionnaire. Other variables examined included background information, experiences and concerns about developing AD. T-tests and Ordinary Least Square (OLS) hierarchical regressions were used to analyze results.

Results: Similar to previous studies, students' levels of dementia stigma were low to moderate. Negative attributions were consistently and significantly higher $(\beta=.17$ to $.33, p<.01)$, and positive attributions were significantly lower $(\beta=-.26, p<.01)$ when the target person was younger rather than older.

Conclusion: The differences in stigmatic beliefs towards a younger and older person with AD point to the theoretical and practical importance of clearly stating the age of the target person in stigma studies as well as in programs aimed at reducing public stigma towards persons with AD.
\end{abstract}

Keywords: Attributional model, Dementia, Young-onset dementia, Late-onset dementia, Public stigma

\section{Background}

Driven by the increasing rates of dementia worldwide [1], public health and research attention is currently dominated by efforts to decrease stigmatic beliefs towards persons with dementia, in general, and Alzheimer's disease (AD), in particular. This is reflected in all National Dementia Strategy programs implemented in a variety of countries [2], as well as in the increasing amount of studies assessing stigma among the general

\footnotetext{
* Correspondence: werner@research.haifa.ac.il

${ }^{1}$ Department of Community Mental Health, University of Haifa, Haifa, Israel Full list of author information is available at the end of the article
}

public (see reviews by Herrmann et al. 2018 [3]; Nguyen \& Li, 2018 [4];Werner, 2014 [5]). Despite the importance of the studies assessing public stigma towards persons with $\mathrm{AD}$, it should be noted that they have predominantly concentrated on stigma directed towards persons with late-onset dementia (LOD). While LOD, defined as onset dementia at the age of 65 and over, is the most common type of dementia, assessing stigmatic beliefs towards persons with onset dementia under the age of 65 - called young-onset dementia (YOD) - is very important for several reasons. First, although sharing the same neuropathological characteristics, both types of dementia

(c) The Author(s). 2020 Open Access This article is licensed under a Creative Commons Attribution 4.0 International License, which permits use, sharing, adaptation, distribution and reproduction in any medium or format, as long as you give appropriate credit to the original author(s) and the source, provide a link to the Creative Commons licence, and indicate if changes were made. The images or other third party material in this article are included in the article's Creative Commons licence, unless indicated otherwise in a credit line to the material. If material is not included in the article's Creative Commons licence and your intended use is not permitted by statutory regulation or exceeds the permitted use, you will need to obtain permission directly from the copyright holder. To view a copy of this licence, visit http://creativecommons.org/licenses/by/4.0/ The Creative Commons Public Domain Dedication waiver (http://creativecommons.org/publicdomain/zero/1.0/) applies to the data made available in this article, unless otherwise stated in a credit line to the data. 
differ in several features such as the rate of progression of the disease, genetic characteristic, and the presentation of behavioral problems [6]. Second, an extensive body of research has demonstrated that sigmatic experiences are common in the lives of persons with YOD, as well as among those surrounding them, such as family and professional caregivers [7-10]. Finally, since the internalization of stigma is closely associated to the stigmatic beliefs held by the public [11-13], evaluating public stigma towards younger persons with the disease - i.e., with young-onset dementia - is of the utmost importance.

Thus, the aim of the present study was to address this gap by comparing college students' stigmatic beliefs towards an older and a younger person with $\mathrm{AD}$, using an attributional model of stigma, which assumes that stigma includes three types of attributions: cognitive attributions or stereotypes about the person with the disease; emotional attributions, including negative and positive emotions; and behavioral attributions, including behavioral discrimination as well as willingness to help. Wile this conceptualization was developed originally for mental illness stigma [14], a recent study demonstrated that public stigma in the area of dementia is characterized by a similar cognitive, emotional, and behavioral process [15].

\section{Methods}

\section{Study design and participants}

This study used a cross-sectional design with a convenience sample of college students.

Using Green formula [16] the minimum sample required was 322. By assuming 30\% dropout rate, a total of 494 college students were asked to participate in the study. Of these, 119 were excluded: nine because of language problems and 110 because they did not complete the questionnaire in its entirety. Thus, data from 375 students were available, rendering a response rate of $75.9 \%$. The majority of the participants were female (58.9\%), Jewish (64.3\%), born in Israel (58.4\%), not married (86.4\%). Regarding their study characteristics, the majority were undergraduate students (85.6\%), half (51.5\%) studied social sciences, $31.5 \%$ exact sciences, and the rest humanities and health studies. Their mean age was 25.5 years $(\mathrm{SD}=4.8$, range $18-51)$.

\section{Measures}

The following instruments were used:

\section{Dependent variables - public stigma towards a person with} $A D$

An adapted version of the Attribution Questionnaire 27 [AQ-27; 14] was used. The adaptation entailed replacing mental illness with $\mathrm{AD}$, and the inclusion of two items assessing lack of aesthetics: To what extent do you think Sara is filthy/smelly?). The inclusion of items assessing aesthetic was based on previous findings stressing the importance of these cognitive attributions for dementia stigma [13, 15]. All items were rated on a 9-point, Likert-type scale, ranging from $1=$ not at all to $9=$ very much, and tapping three dimensions of stigma - cognitive attributions (dangerousness, responsibility, and lack of aesthetics), emotional reactions (negative and positive), and discriminatory behavior (segregation, treatment coercion, and helping behaviors). The adapted version of the instrument was validated in a previous study, and good to very good internal reliability (Cronbach alphas ranging from .70 for responsibility to .86 for negative emotions, were found [15].

\section{Independent variables}

These included socio-demographic characteristics, and health beliefs regarding AD.

Socio-demographic characteristics included age, gender (male and female), majority (Jewish) or minority (non-Jewish) group, and area of study (health and other).

Experiences and concerns of developing $A D$ : These included familiarity with the disease, and worry about developing it.

Familiarity was assessed by asking participants if they knew someone with Alzheimer's disease among their relatives or acquaintances.

Worry about developing Alzheimer's disease was assessed by a single question: "How much do you worry that you will develop Alzheimer's disease?" Answers were rated on a 5-point Likert-type scale, ranging from $1=$ not at all worried to $5=$ very worried.

\section{Procedure}

Participants were recruited opportunistically from various colleges in the Northern part of Israel. They were asked to answer a computerized structured questionnaire after being presented with a vignette developed and used in a previous study [17], but describing a female instead of male person with AD (Sara), aged 80 years old (LOD) or 50 years old (YOD). Besides of the age of the person, both vignettes were identical. Each version was assigned randomly, with 159 participants being exposed to the YOD vignette and 211 to the LOD vignette. No statistically significant differences were found in the socio-demographic or academic characteristics of the participants in each group or in their health beliefs regarding $\mathrm{AD}$. It took approximately $15 \mathrm{~min}$ to complete the questionnaire.

\section{Statistical analyses}

Descriptive statistics (percentages, means, and standard deviations) were used to describe the sample and the 
main variables. T-tests were used to assess differences in attributions of stigma according to the age of the person with $\mathrm{AD}$ described in the vignette. Finally, Ordinary Least Squares (OLS) hierarchical regressions were conducted in order to examine the effect of the age of the person with $\mathrm{AD}$ on stigmatic attributions in each one of the stigma dimensions. In the first step of the regressions, we included the age of the person with $\mathrm{AD}$ as presented in the vignettes. In the second step, sociodemographic factors were entered, followed by health beliefs about Alzheimer's disease, in the third step. We tested for multicollinearity, and the results indicated that it was not a concern in our model. Variance inflation factor (VIF) did not exceed 2.3.

\section{Ethical considerations}

The study's protocol was approved by the Ethics Committee of the University of Haifa. All potential participants were given and read an informed consent form describing the importance of the study, its anonymity, and the possibility to refuse to participate without any consequences. The students were required to sign an informed consent form before starting to answer the questionnaire.

\section{Results}

Overall, as can be observed in Fig. 1, regardless of which vignette was presented and with the exception of coercion, college students' stigmatic attributions were below the neutral score of 4.5, reflecting low to moderate levels of stigma towards a person with AD. However, participants exposed to the vignette presenting a person with YOD reported significantly higher levels of cognitive attributions, negative emotions, and attributions of segregation and coercion, than those exposed to the LOD vignette. Positive emotions and willingness to help were significantly lower in the group exposed to the YOD, compared to those exposed to the LOD vignette. Moreover, results of the hierarchical regressions (Table 1) showed that the age of the person with $\mathrm{AD}$ had the strongest influence on explaining dangerousness $\left(R^{2}=.10\right)$, negative reactions $\left(R^{2}=.10\right)$, positive reactions $\left(R^{2}=.06\right)$, treatment coercion $\left(R^{2}=.04\right)$, and helping behaviors $\left(R^{2}=.06\right)$. While age, gender, and area of study were not significantly associated with any of the stigma variables, participants pertaining to a minority (non-Jewish) group reported higher levels of stigmatic beliefs compared to those pertaining to a majority (Jewish) group. More specifically, this variable was the most important determinant of lack of aesthetics (it increased the explained variance by $4 \%$ when added in Step 2), as well as of responsibility (it increased the explained variance by $10 \%$ when added in Step 2), and institutionalization (it increased the explained variance by 7\% when added in Step 2). Experiences and concerns about developing $\mathrm{AD}$ had a very small influence on explaining stigma attributions for all dimensions.

\section{Discussion}

This study investigated whether differences exist among college students' stigmatic attributions towards a person with YOD or LOD. Overall, similar to other studies conducted with the general public [15, 18-23], stigmatic attributions towards a person with $\mathrm{AD}$ were low to moderate in our sample of relatively young college students. This calls for special attention, particularly since it was established that stigmatic processes, in general, begin at a young age [24], and specifically in regards to

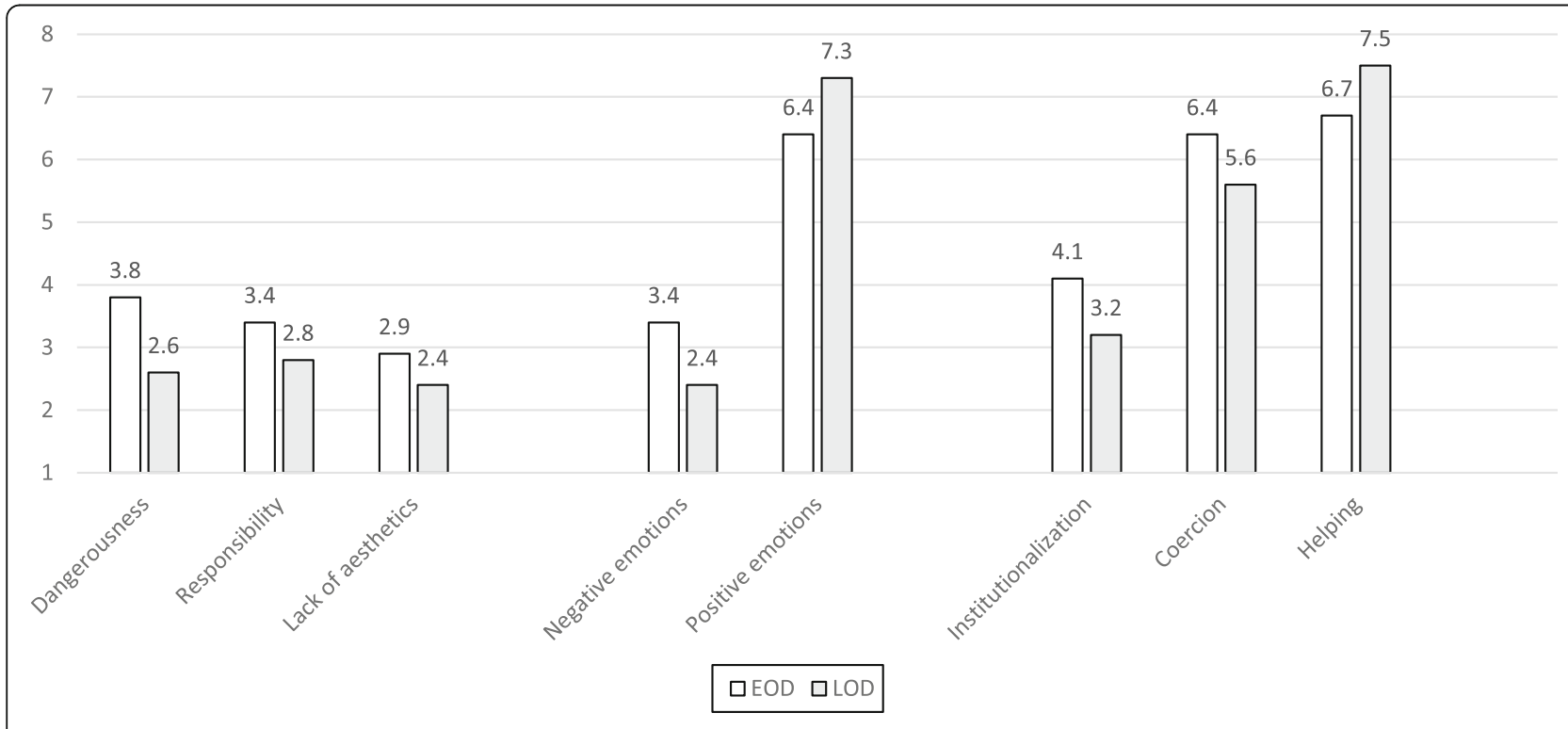

Fig. 1 College students' stigmatic attributions regarding persons with YOD and LOD 
Table 1 Hierarchical regressions assessing the effect of the age of the person described in the vignette $(n=375)$

\begin{tabular}{|c|c|c|c|c|c|c|c|c|}
\hline & \multicolumn{3}{|c|}{ Cognitive dimension } & \multicolumn{2}{|c|}{ Emotional reactions } & \multicolumn{3}{|c|}{ Behavioral attributions } \\
\hline & Dangerousness & $\begin{array}{l}\text { Lack of } \\
\text { Aesthetics }\end{array}$ & Responsibility & $\begin{array}{l}\text { Negative } \\
\text { Reactions }\end{array}$ & $\begin{array}{l}\text { Positive } \\
\text { Reactions }\end{array}$ & Institutionalization & $\begin{array}{l}\text { Treatment } \\
\text { Coercion }\end{array}$ & Helping \\
\hline \multicolumn{9}{|l|}{ Step 1} \\
\hline LOD/YOD & $.33^{* * *}$ & $.17^{* *}$ & $.20^{* *}$ & $.33^{* * *}$ & $-.26^{* * *}$ & $.21^{* * *}$ & $.19^{* * *}$ & $-.26^{* * *}$ \\
\hline Adjusted $\mathrm{R}^{2}$ & .10 & .02 & .03 & .10 & .06 & .04 & .04 & .06 \\
\hline \multicolumn{9}{|l|}{ Step 2} \\
\hline Age & .01 & .05 & .03 & .01 & .03 & -.07 & .03 & -.03 \\
\hline Gender & -.01 & .03 & -.05 & -.03 & .10 & -.07 & .01 & .10 \\
\hline $\begin{array}{l}\text { Jewish/Non- } \\
\text { Jewish }\end{array}$ & $.21^{* * *}$ & $.19^{*}$ & $.29^{* * *}$ & $.20^{* *}$ & .01 & $.27^{* * *}$ & $.18^{* *}$ & -.02 \\
\hline Area of study & -.09 & -.07 & $-.17^{* *}$ & $-.13^{*}$ & .10 & .02 & .09 & .05 \\
\hline Adjusted $\mathrm{R}^{2}$ & .14 & .06 & .13 & .15 & .06 & .11 & .06 & .06 \\
\hline \multicolumn{9}{|l|}{ Step 3} \\
\hline $\begin{array}{l}\text { Familiarity with } \\
A D\end{array}$ & .02 & $-.14^{*}$ & $.11^{*}$ & -.01 & -.07 & .02 & $-.17^{* *}$ & -.01 \\
\hline $\begin{array}{l}\text { Concern about } \\
A D\end{array}$ & .04 & .04 & .02 & .06 & .09 & .10 & $.20^{* * *}$ & $.14^{*}$ \\
\hline $\begin{array}{l}\text { Total Adjusted } \\
\mathrm{R}^{2}\end{array}$ & .14 & .07 & .15 & .15 & .07 & .12 & .10 & .08 \\
\hline
\end{tabular}

dementia, stigmatic attributions increase with age [22, $25,26]$.

Most importantly, our study expands these findings by demonstrating that stigmatic attributions elicited by a person with $\mathrm{AD}$ vary according to the age of the target person. Indeed, college students consistently reported higher stigmatic attributions when presented with a younger person with dementia than with an older one. Several explanations might be provided for this finding: some relate to the concept of stigma in the area of $\mathrm{AD}$ and some to general attitudes towards older persons.

Public stigma is defined as laypersons' perceptions of a person or a group as having a cue or mark which makes them different or abnormal [27]. Given the characteristics of $\mathrm{AD}$ and its clear association with older age [28], we can hypothesize that the higher levels of stigmatic beliefs reported toward the younger person with $\mathrm{AD}$ were a result of her being perceived as "different" or "abnormal". This explanation is supported by studies examining persons with YOD and their caregivers, which described stigma as a reoccurring theme because of the uncommon situation of encountering a relatively young person with the disease [29]. Moreover, it has been stated that laypersons' stigmatic beliefs are associated with perceptions of threat associated with the stigmatized group [30]. In view of the relatively young age of our sample, we can assume that the feelings of threat will be higher for those exposed to the vignette describing a person closer to their age.
Alternatively, we can assume that the differences in stigmatic beliefs associated with the age of the person with $\mathrm{AD}$ do not stem, as suggested above, from higher stigmatic beliefs directed towards the younger person, but from lower stigmatic beliefs towards the older person with $\mathrm{AD}$ caused by paternalistic stereotypes. While paternalistic stereotypes, defined as attributions attached to a person as needing care and help, were previously studied mainly in regard to persons with mental illness [31], studies showed that older healthy targets also elicit more positive emotions than younger targets, even if they are perceived as less competent [32, 33].

Finally, the age of the person described in the vignette remained a significant predictor of all stigmatic attributions, even after including other variables. Moreover, it emerged as the most important determinant for two negative attributions (dangerousness, and negative reactions), and the second most important determinant for the rest of the attributions, apart from ethnicity. These findings call for future studies in the area of dementia stigma to explicitly state the age of the person with the disease.

In addition to the contribution of the age of the person with $\mathrm{AD}$ to the explanation of stigmatic attributions, our findings showed that pertaining to a minority (non-Jewish) group was consistently associated with increased stigma. A similar trend was found in an Israeli sample of high school students [34], stressing the importance of cultural factors to the formation of stigmatic beliefs. 
Finally, the lack of significant relationships with health beliefs is noteworthy, as this is a central factor in attribution models of stigma [14]. While this might be a result of the relatively young age of our sample, future studies should try to further examine these associations.

Several limitations should be noted before we discuss the implications of our results. First, the study employed a non-random sample. Participation in the study was voluntary and no information was available about the characteristics of those who did not participate. Finally, the cross-sectional design of our study does not allow for a causal interpretation of the results.

Our findings should also be considered in the context of our measurement methods. The use of self-reported measures might be associated with social desirability bias and item non-response. However, only 11 to $14 \%$ of the participants did not answer one of the attribution items. Moreover, we hope that the anonymity of the questionnaires encouraged students to be honest in their responses. Another limitation might be the use of vignettes, which do not necessarily reflect real-life situations [35]. However, vignettes are commonly used to assess stigmatic beliefs in a variety of conditions [36, 37], and they have been especially useful for testing hypotheses [17, 20, 38-40]. Finally, it should be noted that our vignettes did not use the terms "young/late onset dementia", but rather varied the age of the person described in them. Future studies might want to assess the effect of using these labels on stigmatic beliefs towards a person with $\mathrm{AD}$.

\section{Conclusions}

Notwithstanding these limitations, this study has important implications. First, it supports recent findings [10] showing that the use of an expanded model of Attribution Theory provides an adequate conceptual framework for understanding dementia stigma. Second, the differences found in the stigmatic beliefs attributed to a younger or an older person with $\mathrm{AD}$ point to the theoretical and practical importance of clearly stating the age of the target person in stigma studies and in anti-stigma campaigns in the area of $\mathrm{AD}$.

\section{Abbreviations}

AD: Alzheimer's disease; LOD: Late-onset dementia; OLS: Ordinary Least Squares; VIF: Variance inflation factor; YOD: Young-onset dementia

\section{Acknowledgements}

Not applicable.

\section{Authors' contributions}

PW contributed to the designing of the study, interpretation of the data, and led the writing of the manuscript. LRT collected the data and conducted data analyses. PC critically read and commented on the manuscript, and on its conceptual and practical implications. All authors read and approved the final manuscript.
Funding

Not applicable.

\section{Availability of data and materials}

The datasets used are available from the corresponding author on reasonable request.

\section{Ethics approval and consent to participate}

The study's protocol was approved by the Ethics Committee of the University of Haifa. All potential participants were given and read an informed consent form describing the importance of the study, its anonymity, and the possibility to refuse to participate without any consequences. The students were required to sign an informed consent form before starting to answer the questionnaire.

\section{Consent for publication}

Not applicable.

\section{Competing interests}

The authors declare that they have no competing interests.

\section{Author details}

${ }^{1}$ Department of Community Mental Health, University of Haifa, Haifa, Israel. ${ }^{2}$ Illinois Institute of Technology, Chicago, USA.

Received: 1 November 2019 Accepted: 4 March 2020 Published online: 14 March 2020

\section{References}

1. Stephan B, Birdi R, Yee Hing Tang E, Cosco TD, Donini LM, et al. Secular trends in dementia prevalence and incidence worldwide: a systematic review. J Alzheimers Dis. 2018;66(2):653-80.

2. Chow S, Chow R, Wan A, Lam HR, Taylor K, Bonin K, et al. National dementia strategies: what should Canada learn? Can Geriatr J. 2018;21(2): 173-209.

3. Herrmann LK, Welter E, Leverenz J, Lerner AJ, Udelson N, Kanetsky C, et al. A systematic review of dementia-related stigma research: can we move the stigma dial? Am J Geriatr Psychiatry. 2018;26(3):361-31.

4. Nguyen T, Li X. Understanding public-stigma and self-stigma in the context of dementia: a systematic review of the global literature. Dementia. 2020; 19(2):148-81.

5. Werner P. Stigma and Alzheimer's disease: a systematic review of evidence, theory, and methods. In: Corrigan P, editor. The stigma of disease and disability: understanding causes and overcoming injustices. Washington, DC: American Psychological Association; 2014. p. 223-44.

6. Panegyres PK, Chen HY. Differences between early and late onset Alzheimer's disease. Am J Neurodeger Dis. 2013;2(4):300-6.

7. Ducharme F, Kergoat MJ, Antoine P, Pasquier F, Coulombe R. The unique experience of spouses in early-onset dementia. Am J Alzheimers Dis Other Dement. 2013;28(6):634-41.

8. Holdsworth K, McCabe M. The impact of younger-onset dementia on relationships, intimacy, and sexuality in midlife couples: a systematic review. Int Psychogeriatr. 2018;30(1):15-29.

9. Spreadbury JH, Kipps C. Measuring younger onset dementia: what the qualitative literature reveals about the 'lived experience' for patients and caregivers. Dementia. 2019;18(2):579-98.

10. Werner P, Shpigelman CN, Raviv Turgeman L. Family caregivers' and professionals' stigmatic experiences with persons with early-onset dementia: a qualitative study. Scand J Caring Sci. 2019. https://doi.org/10.1111/scs. 12704.

11. Corrigan PW, Miller FE. Shame, blame, and contamination: a review of the impact of mental illness stigma on family members. J Ment Health. 2004; 13(6):537-48.

12. Mak WW, Cheung RY. Affiliate stigma among caregivers of people with intellectual disability or mental illness. J Appl Res Intellect Disabil. 2008;21(6): $532-45$.

13. Werner $\mathrm{P}$, AboJabel H. Who internalizes courtesy stigma and how? A study among Israeli Arab family caregivers of persons with dementia. Aging Ment Health. 2019. https://doi.org/10.1080/13607863.2019. 
14. Corrigan P, Markowitz FE, Watson A, Rowan D, Kubiak MA. An attribution model of public discrimination towards persons with mental illness. J Health Soc Behav. 2003;44(2):162-79.

15. Werner P, Kalaitzaki AE, Spitzer N, Raviv Turgeman L, Koukouli S, Tzriraki C. Stigmatic beliefs towards persons with dementia: comparing Israeli and Greek college students. Int Psychogeriatr. 2019;31(10):1393-401.

16. Green SB. How many subjects does it take to do a regression analysis. Mutivariate Behav Res. 1991;26(3):499-510.

17. Werner P, Davidson M. Emotional reactions of lay persons to someone with Alzheimer's disease. Int J Geriatr Psychiatry. 2004;19(4):391-7.

18. Adebiyi AO, Fagbola MA, Olakehinde O, Ogunniyi A. Enacted and implied stigma for dementia in a community in south-West Nigeria. Psychogeriatrics. 2016;16(4):268-73.

19. Angermeyer MC, Matschinger $\mathrm{H}$, Schomerus $\mathrm{G}$. Attitudes towards psychiatric treatment and people with mental illness: changes over two decades. Br J Psychiatry. 2013;203(2):146-51.

20. Blay SL, Peluso ÉTP. Public stigma: the community's tolerance of Alzheimer disease. Am J Geriatr Psychiatry. 2010;18(2):163-71.

21. Johnson R, Harkins K, Cary M, Sankar P, Karlawish J. The relative contributions of disease label and disease prognosis to Alzheimer's stigma: a vignette-based experiment. Soc Sci Med. 2015;143:117-27.

22. Piver LC, Nubukpo P, Faure A, Dumoitier N, Couratier P, Clément JP. Describing perceived stigma against Alzheimer's disease in a general population in France: the STIG-MA survey. Int J Geriatr Psychiatry. 2013;28(9):933-8.

23. Woo BK. Knowledge of dementia among Chinese American immigrants. Asian J Psychiatr. 2013;6(4):351-2.

24. Mulvey KL, Hitti A, Killen M. The development of stereotyping and exclusion. Wiley Interdiscip Rev Cogn Sci. 2010;1(4):597-606.

25. Stites SD, Johnson R, Harkins K, Sankar P, Xie D, Karlawish J. Identifiable characteristics and potentially malleable beliefs predict stigmatizing attributions toward persons with Alzheimer's disease dementia: results of a survey of the US general public. Health Commun. 2018;33(3):264-73.

26. Werner P. Lay perceptions about mental health: where is age and where is Alzheimer's disease? Int Psychogeriatr. 2005;17(3):371-82.

27. Corrigan PW. Mental health stigma as social attribution: implications for research methods and attitude change. Clin Psychol-Sci Pr. 2000;7:48-67.

28. Friedman DB, Becofsky K, Anderson LA, Bryant LL, Hunter RH, Ivey SL, et al. Public perceptions about risk and protective factors for cognitive health and impairment: a review of the literature. Int Psychogeriatr. 2015;27(8):1263-75.

29. Millenaar JK, Bakker C, Koopmans RT, Verhey FR, Kurz A, Vugt ME. The care needs and experiences with the use of services of people with young-onset dementia and their caregivers: a systematic review. Int J Geriatr Psychiatry. 2016;31(12):1261-76

30. Martin JK, Pescosolido BA, Tuch SA. Of fear and loathing: the role of disturbing behavior' labels, and causal attributions in shaping public attitudes toward people with mental illness. J Health Soc Behav. 2000;41(2): 208-23.

31. Charles JL, Bentley KJ. Stigma as an organizing framework for understanding the early history of community mental health and psychiatric social work. Soc Work Ment Health. 2016;14(2):149-73.

32. Cuddy AJ, Fiske ST. Doddering but dear: process, content, and function in stereotyping of older persons. In: Nelson TD, editor. Ageism: stereotyping and prejudice against older persons. London: The MIT Press; 2002. p. 3-26.

33. Cuddy AJ, Norton MI, Fiske ST. This old stereotype: the pervasiveness and persistence of the elderly stereotype. Aust J Soc Issues. 2005;61(2):267-85.

34. Werner $P, A b o J a b e l ~ H$, Reuveni $Y$, Prilutzki D. Stigmatic beliefs toward a person with Alzheimer's disease among high school students: does majority-minority status make a difference? Educ Gerontol. 2017;43(12):609-18.

35. Ruggs EN, King EB, Hebbl M, Fitzsimmons M. Assessment of weight stigma. Obes Facts. 2010;3(1):60-9.

36. Link BG, Yang LH, Phelan JC, Collins PY. Measuring mental illness stigma. Schizophr Bull. 2014;30(3):511-41.

37. Puhl RM, Heuer CA. The stigma of obesity: a review and update. Obesity. 2009;17(5):941-64.

38. Bourkel E, Ferring D, Weber G. Perceived rights of and social distance to people with Alzheimer's disease. J Gerontopsychol Geriatric Psychiatry. 2012; 25(1):25-32

39. Wadley VG, Haley WE. Diagnostic attributions versus labeling impact of Alzheimer's disease and major depression diagnoses on emotions, beliefs, and helping intentions of family members. J Gerontol B Psychol Sci Soc Sci. 2001;56(4):244-22.
40. Werner P. Lay perceptions regarding the competence of persons with Alzheimer's disease. Int J Geriatr Psychiatry. 2006;21(7):674-80.

\section{Publisher's Note}

Springer Nature remains neutral with regard to jurisdictional claims in published maps and institutional affiliations.

\section{Ready to submit your research? Choose BMC and benefit from:}

- fast, convenient online submission

- thorough peer review by experienced researchers in your field

- rapid publication on acceptance

- support for research data, including large and complex data types

- gold Open Access which fosters wider collaboration and increased citations

- maximum visibility for your research: over $100 \mathrm{M}$ website views per year

At $\mathrm{BMC}$, research is always in progress.

Learn more biomedcentral.com/submissions 